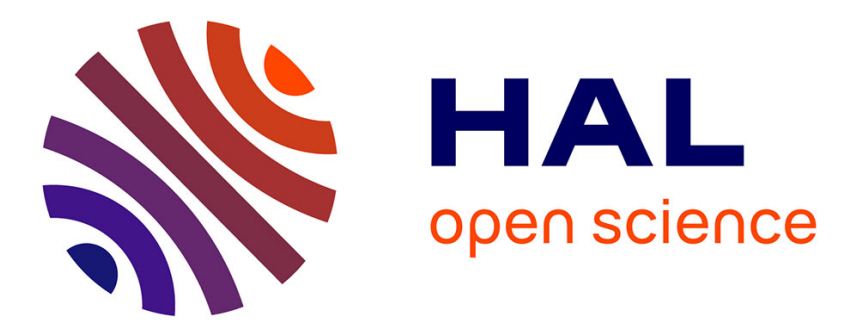

\title{
SPIRIT. SPOT 5 stereoscopic survey of Polar Ice: Reference Images and Topographies during the fourth International Polar Year (2007-2009)
}

Jérôme Korona, Etienne Berthier, Marc Bernard, Frédérique Rémy, Eric Thouvenot

\section{To cite this version:}

Jérôme Korona, Etienne Berthier, Marc Bernard, Frédérique Rémy, Eric Thouvenot. SPIRIT. SPOT 5 stereoscopic survey of Polar Ice: Reference Images and Topographies during the fourth International Polar Year (2007-2009). ISPRS Journal of Photogrammetry and Remote Sensing, 2009, 64, pp.204212. 10.1016/j.isprsjprs.2008.10.005 . hal-00397912

\section{HAL Id: hal-00397912 https://hal.science/hal-00397912}

Submitted on 23 Jun 2009

HAL is a multi-disciplinary open access archive for the deposit and dissemination of scientific research documents, whether they are published or not. The documents may come from teaching and research institutions in France or abroad, or from public or private research centers.
L'archive ouverte pluridisciplinaire HAL, est destinée au dépôt et à la diffusion de documents scientifiques de niveau recherche, publiés ou non, émanant des établissements d'enseignement et de recherche français ou étrangers, des laboratoires publics ou privés. 


\title{
SPIRIT. SPOT 5 stereoscopic survey of Polar Ice: Reference Images and Topographies during the fourth International Polar Year (2007-2009)
}

\author{
Jérôme Korona ${ }^{1}$, Etienne Berthier ${ }^{2,3}$, Marc Bernard $^{1}$, Frédérique Rémy $^{2,3}$, Eric Thouvenot $^{4}$ \\ ${ }^{1}$ Spot Image, 5 rue des Satellites, BP 14359, F31030 Toulouse Cedex 4, France \\ ${ }^{2}$ Université de Toulouse; UPS (OMP-PCA); LEGOS; 14 Av. Edouard Belin, F-31400 Toulouse, France \\ ${ }^{3}$ CNRS; LEGOS; 14 Avenue Ed. Belin, F-31400 Toulouse, France \\ ${ }^{4}$ CNES, 18 av. E. Belin, 31401 Toulouse Cedex 9, France \\ * Corresponding author \\ 14 av. Ed. Belin \\ 31400 Toulouse \\ France \\ Email: etienne.berthier <at> legos.obs-mip.fr
}

To be cited as:

Korona J., Berthier E., Bernard M., Rémy F. \& Thouvenot E. SPIRIT. SPOT 5 stereoscopic survey of Polar Ice: Reference Images and Topographies during the fourth International Polar Year (2007-2009). ISPRS J Photogramm, 64, 204-212, doi:10.1016/j.isprsjprs.2008.10.005, 2009

\section{ISPRS KEYWORDS:}

Glaciology; Snow Ice; Climate; SPOT; DEM/DTM; Cartography; Change Detection; Monitoring OTHER KEYWORDS:

International Polar Year; Antarctica; Greenland; Ice Cap; Glacier; Climate Change; Jakobshavn Isbrae; SPOT 5 HRS; Remote Sensing

\begin{abstract}
Monitoring the evolution of polar glaciers, ice caps and ice streams is of utmost importance because they constitute a good indicator of global climate change and contribute significantly to ongoing sea level rise. Accurate topographic surveys are particularly relevant as they reflect the geometric evolution of ice masses. Unfortunately, the precision and/or spatial coverage of current satellite missions (radar altimetry, ICESat) or field surveys are generally insufficient. Improving our knowledge of the topography of Polar Regions is the goal of the SPIRIT (SPOT 5 stereoscopic survey of Polar Ice: Reference Images and Topographies) international polar year (IPY) project. SPIRIT will allow (1) the acquisition of a large archive of SPOT 5 stereoscopic images covering most polar ice masses and, (2) the delivery of digital terrain models (DTM) to the scientific community.

Here, we present the architecture of this project and the coverage achieved over northern and southern polar areas during the first year of IPY (July 2007 to April 2008). We also provide the first accuracy assessments of the SPIRIT DTMs. Over Jakobshavn Isbrae (West Greenland), SPIRIT elevations are within $\pm 6 \mathrm{~m}$ of ICESat elevations for $90 \%$ of the data. Some comparisons with ICESat profiles over Devon ice cap (Canada), St Elias Mountains (Alaska) and west Svalbard confirm the good overall quality of the SPIRIT DTMs although large errors are observed in the flat accumulation area of Devon ice cap. We then demonstrate the potential of SPIRIT DTMs for mapping glacier elevation changes. The comparison of summer-2007 SPIRIT DTMs with October-2003 ICESat profiles shows that the thinning of Jakobshavn Isbrae (by 30 to $40 \mathrm{~m}$ in 4 years) is restricted to the fast glacier trunk. The thinning of the coastal part of the ice stream (by over $100 \mathrm{~m}$ ) and the retreat of its calving front (by up to $10 \mathrm{~km}$ ) are clearly depicted by comparing the SPIRIT DTM to an ASTER April-2003 DTM.
\end{abstract}




\section{INTRODUCTION}

During the last two decades, the cryosphere has been the theatre of rapid and major changes. Shrinkage of mountain glaciers and ice caps has accelerated during the past ten years, with contribution to sea level rise growing from $0.33 \mathrm{~mm}$ per year (for the 1961-1990 period) to 0.8 mm per year (for the 2001-2004 period) (Kaser et al., 2006). Break up of Larsen A and B ice shelves in the Antarctic Peninsula have led to the thinning and acceleration of the glaciers located upstream (Rott et al., 1996; Scambos et al., 2004). Major changes in the ice dynamics have also been recently detected in Greenland, leading to rapid ice loss (Howat et al., 2007; Rignot and Kanagaratnam, 2006). Thus, the cryosphere appears has one of the major actor and indicator of ongoing climate change (IPCC International Panel on Climate Change, 2007).

Yet, the topography of glaciers, ice caps and ice shelves remains poorly known. Obtaining a homogenous and precise topography of these remote regions is important to characterize their response to recent climate change, quantify their contribution to sea level rise and detect future evolution. Furthermore, the topography of ice masses is a free surface reflecting external forcings and physical processes within the ice (Remy et al., 1999). It can be used to test ice dynamic models or as an initial condition to predict their evolution (Remy and Parrenin, 2004; Ritz et al., 2001). Its knowledge is also crucial for accurate dating of ice cores (Parrenin et al., 2004).

The topography of polar ice masses is still poorly known because in situ observations are difficult and sparse. Space-borne measurements of the ice topography are also challenging and not always a priority. For example, regions north of $60^{\circ} \mathrm{N}$ and south of $56^{\circ} \mathrm{S}$, were not surveyed by the Shuttle Radar Topography Mission (SRTM) in February 2000 (Rabus et al., 2003). Satellite radar altimeters on-board ERS1, ERS2 and Envisat have the capability to measure the surface elevation of large ice masses with a good relative precision in cases where the slopes are gentle. The geodetic mission of ERS-1 has provided precise topography with a resolution of $2 \mathrm{~km}$. Since, the 35-day cycles of ERS-2 and Envisat have a cross track distance of $50 \mathrm{~km}$ at latitude $70^{\circ}$ so that small scale features of the topography cannot be captured using space-borne radar altimeters. Moreover, this technique is not effective for steeper areas and, thus, cannot accurately map most mountain glaciers, ice caps and the coastal regions of the two ice sheets. The GLAS (Geosciences Laser Altimeter System) instrument on ICESat is less limited than the microwave altimeter. It surveys altimetric profiles with a laser footprint of $\sim 70$ m every $\sim 170 \mathrm{~m}$ along track (Zwally et al., 2002). The distance between two consecutive tracks varies from $2.5 \mathrm{~km}$ at latitude of $80^{\circ}$ to $15 \mathrm{~km}$ at the Equator. GLAS provides precise $( \pm 15 \mathrm{~cm})$ measurements of ice surface elevation (Shuman et al., 2006) but the profiles remain relatively spaced to map the geometric evolution of the major ice streams.

Despite the strong albedo and the lack of texture of snow or ice, stereoscopic optical images have already proved to be a valuable mean to obtain large-scale topographies of ice masses in different types of relief, from steep alpine glaciers (Berthier et al., 2004) to fast flowing outlet glaciers of the Greenland ice sheet (Stearns and Hamilton, 2007). In particular, good results have already been obtained over Alaska icefields and the Antarctic Peninsula during preliminary studies using the HRS (High Resolution Stereoscopic) sensor on-board SPOT 5 (Berthier and Toutin, 2008). Following these promising results and to contribute to the fourth International Polar Year (IPY) in the framework of the GIIPSY project (Global Interagency IPY Polar Snapshot Year; 
http://bprc.osu.edu/rsl/GIIPSY/), the French Space Agency (Centre National d'Etudes Spatiales, CNES), Spot Image and the LEGOS (Laboratoire d'Etudes en Géophysique et Océanographie Spatiales) launched the SPIRIT project: SPOT 5 stereoscopic survey of Polar Ice: Reference Images and Topographies. The goal of the present article is to describe this project, summarize the first accuracy assessments and demonstrate the glaciological potential of SPIRIT data.

\section{DESIGN OF THE SPIRIT PROJECT}

The main aims of the SPIRIT project are (1) to build a comprehensive archive of SPOT 5 HRS images over polar ice and (2), for selected regions, to produce DTMs and ortho-images that will be delivered for free to the scientific community involved in IPY projects. In this section, we will first present the SPOT 5 HRS sensor, then describe the target areas and the acquisitions obtained so far (as of 17 April 2008) and briefly provide the characteristics of the SPIRIT product (DTMs and ortho-image) that is delivered to the scientific community.

\section{II.1. The HRS sensor onboard SPOT 5}

The HRS sensor, embedded on SPOT 5, was designed for DTM generation by acquiring pairs of images in a single pass of the satellite. It is composed of two telescopes, pointing $20^{\circ}$ toward the rear and $20^{\circ}$ toward the front, respectively, relative to nadir, providing a base-to-height ratio of 0.8 (Toutin, 2001). A $600 \mathrm{~km}$ by $120 \mathrm{~km}$ stereoscopic pair is captured within 180 seconds (Fig. $1)$, with a resolution of $10 \mathrm{~m}$. However, the ground sampling distance is smaller along track $(5 \mathrm{~m})$ than across track $(10 \mathrm{~m})$ to increase the accuracy of the DTMs. The acquisition mode is panchromatic $(0.48 \mu \mathrm{m}-0.71 \mu \mathrm{m})$.

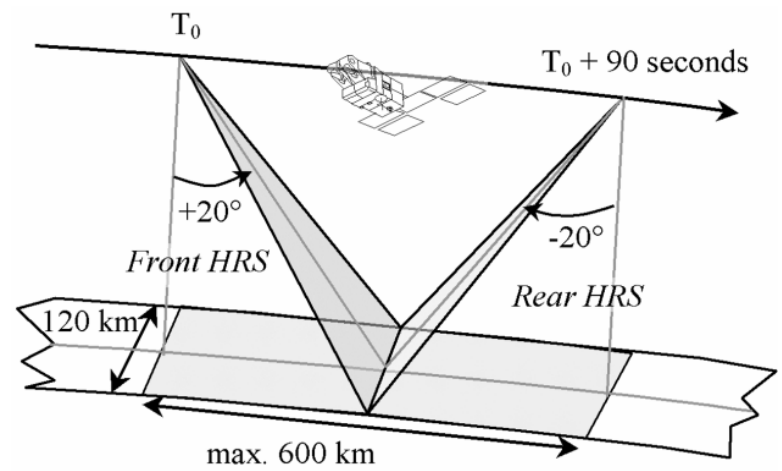

Figure 1: SPOT 5 HRS sensor acquisition geometry. Images with a swath of $120 \mathrm{~km}$ along a segment up to $600 \mathrm{~km}$ are acquired during a descending (north to south) orbit.

The short time separation between the acquisitions of the two scenes of the stereo-pair (90 s) ensures very limited (or no) changes at the glacier surface and nearly identical sun illumination so that the radiometry of the two images is similar. Over ice-free landmasses, HRS provides DTMs with a vertical accuracy of $10 \mathrm{~m}$ with $90 \%$ confidence on surface slopes less than $20 \%$. Thanks to the onboard stellar location unit, using star-tracker data (good low frequency accuracy) and gyroscopes data (good high frequency accuracy), the intrinsic absolute location precision is better than $30 \mathrm{~m}$ rms (Bouillon et al., 2006). 
A more detailed description of the SPOT 5 HRS satellite mission and the accuracy of the HRSderived DTMS can be found in Bouillon et al. (2006).

\section{II.2 Building a SPOT 5 HRS archive over polar ice masses.}

The first step of the SPIRIT project was the selection of target areas and the definition of their relative priority. One major constrain was the $81.15^{\circ}$ north $-81.15^{\circ}$ south acquisition limits of the SPOT 5 orbit. The flat, snow-covered and homogenous central regions of the Antarctic and Greenland ice sheets were deliberately excluded because DTMs derived from stereoscopic optical images generally contain large data gaps over homogeneous regions (Berthier and Toutin, 2008) and, anyway, they would not reach the sub-meter accuracy already obtained using radar or laser altimetric surveys on very smooth topography.

Thus, three groups of target areas were considered: the coastal regions of Antarctica, the margins of the Greenland ice sheet and small glaciers and ice caps that surround the Artic ocean and Antarctica. Overall, these three groups encompass 108 target areas totaling more than 2.5 million square kilometers and classified using three levels of priority (Fig. 2a and 3a):

- Top Priority: fast changing areas in Greenland, Antarctica and rapidly thinning ice caps and icefields (e.g. Pine Island Glacier, Jakobshavn Glacier, Patagonian Icefields, Vatnajökull ice cap, etc.)

- Important Priority: all other major ice streams of Greenland and Antarctica (draining most of the snow that accumulates in their central parts) whose behavior is crucial for the mass balance and dynamics of the polar ice sheets. Identification of all these major outlet glaciers was possible by the mean of InSAR velocity mosaics (Rignot, 2006; Rignot and Kanagaratnam, 2006) and also thanks to two image mosaics derived from MODIS data (Scambos et al., 2007). This intermediate priority level also encompasses some small glaciers and ice caps where fast evolutions have been reported (Alaska, Iceland) or poorly known ones such as Vilchek land Ice cap in Franz Josef Land (Dowdeswell, 2007, personal communication).

- Standard Priority: remaining areas at the periphery of the Greenland and Antarctic ice sheets and other ice-covered regions close to the poles of both hemispheres.

The priority levels can be changed in the course of IPY, in case of spectacular events (ice-shelf break-up for example). Some areas will be acquired twice in order to study their quick (one year) evolution. The Antarctic Peninsula has already been surveyed by SPOT 5 HRS in 2006 and will probably be re-surveyed during the second year of IPY, in 2009. This is why it was not included in the 2008 Southern Hemisphere acquisition campaign.

The SPIRIT project started on $1^{\text {st }}$ July 2007. SPOT 5 HRS images will be acquired, at minimum, until April 2009. The acquisition windows for each hemisphere have been chosen to cope with the polar night and snow cover: June to November for north hemisphere, December to April for south hemisphere, with local variations according to latitude.

The nominal revisit period of HRS, considering its along-track acquisition mode, equals 26 days. However, the polar orbit leads to a shorter revisit period (sometimes 1 or 2 days) between two 
acquisitions at high latitudes. This explains how a significant coverage could already be achieved during the first year of the SPIRIT project over both hemispheres (see below).

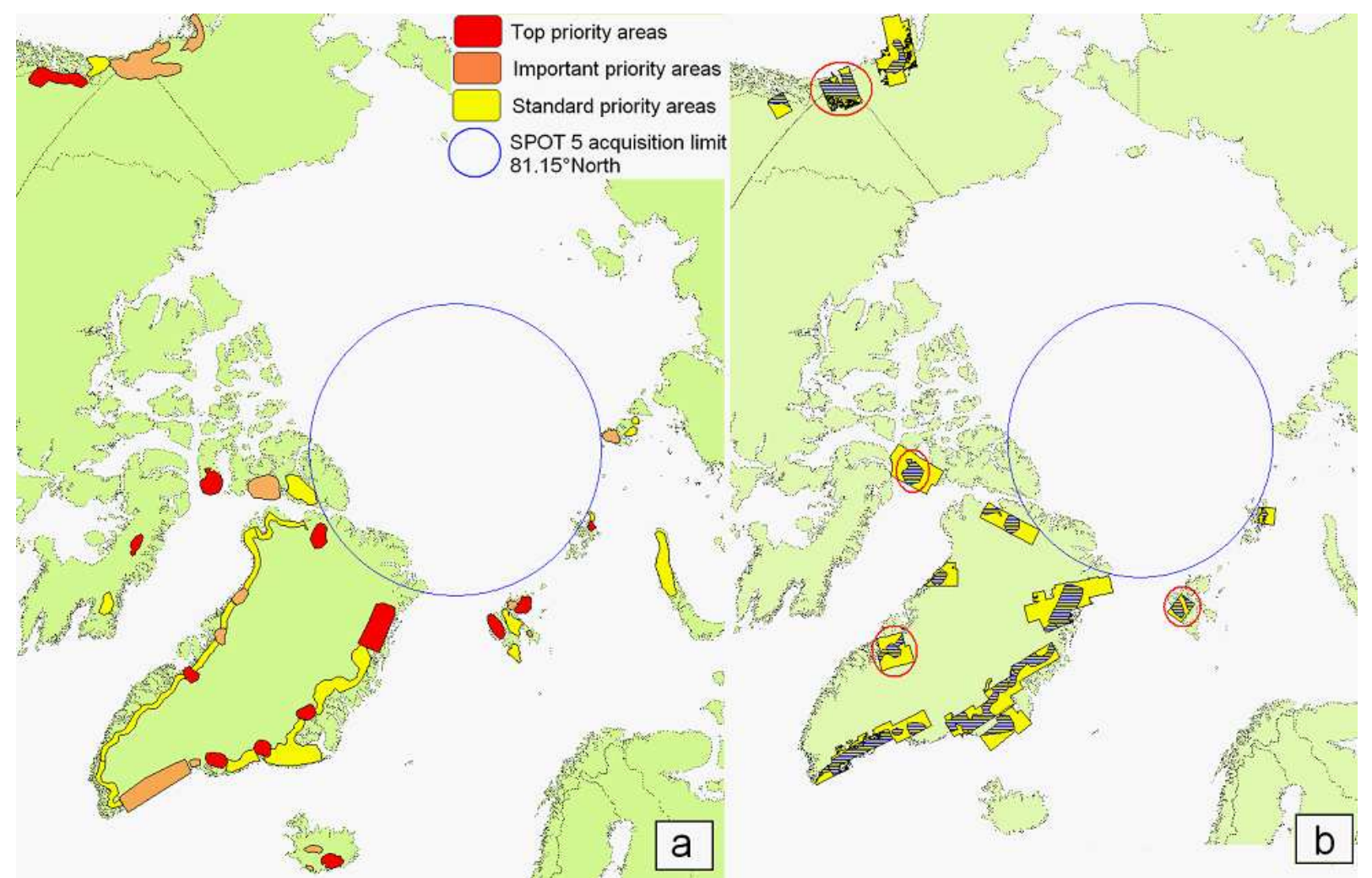

Figure 2: (a) 43 areas of interest for the SPIRIT project in the Northern Hemisphere. They cover about $680,000 \mathrm{~km}^{2}$ (see details in Table 1). (b) Northern Hemisphere SPOT 5 HRS coverage achieved during summer 2007 (from July to October 2007); in yellow the footprints of the HRS images; and dashed, the original area of interest. An updated coverage is available at http://www.spotimage.fr/IPY. The circles locate the four regions used to validate the SPIRIT DTMs (St Elias Mountain, Devon Ice Cap, Jakobshavn Isbrae and north-west Svalbard).

Discriminating snow from cloud in optical panchromatic images is a tough task, almost impossible for the current automatic algorithms, and thus, must be performed by a human operator. To optimize the acquisition campaigns, cloud detection needs to be performed on a daily basis. Indeed, once a region has been covered by cloud-free images, it has to be rapidly excluded from the satellite schedule to task the satellite towards other target areas.

Another key issue is the appropriate setting of the HRS sensor gains. Automatic generation of DTM from optical stereo-images is performed through a matching algorithm. The correlation performs well only if the radiometric range of the images is wide enough to avoid large homogenous areas, which implies that the gain must not be too high (images would be saturated) nor too low (too limited radiometric range). Considering a snow-covered Earth surface (albedo of about 0.9), the best sensor gain is evolving depending on the time of year and the latitude (Raup et al., 2000). Consequently, the gain setting is modified on a weekly basis for each areas of interest in order to insure the best correlation score during the DTM production phase. 

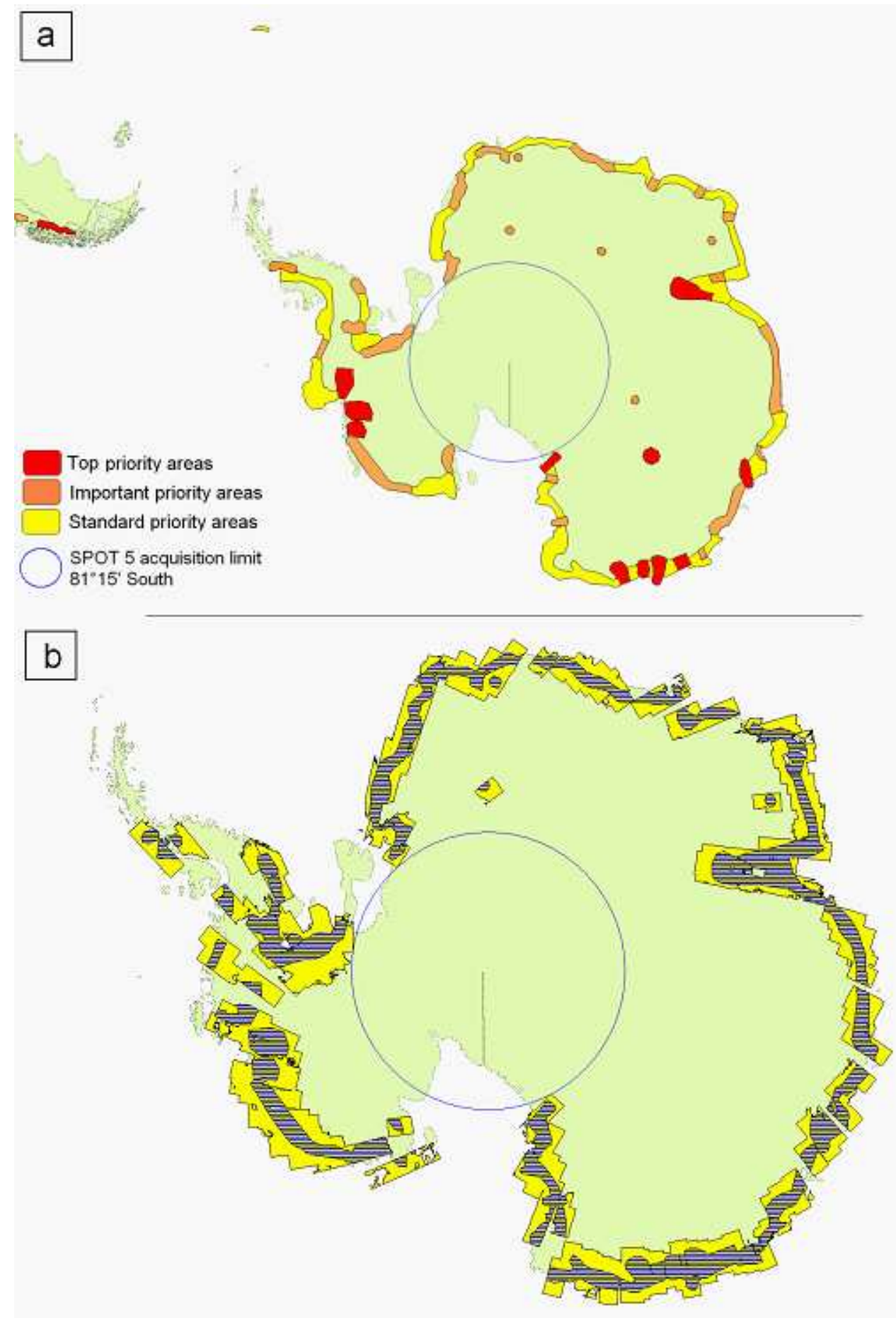

Figure 3: (a) 65 areas of interest for the SPIRIT project in the Southern Hemisphere. They cover about 1,900,000 km² (see details in Table 1). (b) Southern Hemisphere SPOT 5 HRS coverage achieved (as of 17 April 2008) during the 2007-2008 campaign (December 2007 to April 2008); in yellow the footprints of the HRS images; and dashed, the original area of interest. An updated coverage is available at http://www.spotimage.fr/IPY. 
The cloud-free coverage achieved during the 2007 Northern Hemisphere campaign is presented in Fig. 2b. About $44 \%$ of the total arctic targeted surface $\left(\sim 300000 \mathrm{~km}^{2}\right)$ was covered between 1 July and late October 2007. The first Southern Hemisphere campaign (December 2007 to April 2008) was even more successful (Fig. 3b). As of 17 April 2008, 77\% of the targeted areas have already been covered (about $1,480,000 \mathrm{~km}^{2}$ ). This is mainly due to the absence of conflicts in the daily use of SPOT 5 in the south hemisphere and to generally good weather conditions in summer over Antarctica. The details of both campaigns are provided in the Table 1, which gives the area covered for each priority level in each hemisphere and the number of attempts $(60 \mathrm{~km} * 120 \mathrm{~km}$ scenes).

\begin{tabular}{llrrrrr}
\hline Region & Priority & $\begin{array}{c}\text { Area of interest } \\
\left(\mathbf{k m}^{2}\right)\end{array}$ & $\begin{array}{c}\text { Area covered } \\
\left(\mathbf{k m}^{2}\right)\end{array}$ & $\begin{array}{c}\text { Area covered } \\
(\mathbf{\%})\end{array}$ & $\begin{array}{c}\text { Number of } \\
\text { attempts }\end{array}$ \\
\hline \multirow{3}{*}{$\begin{array}{l}\text { North } \\
\text { Hemisphere }\end{array}$} & Top & 179925 & 122965 & 68.6 & 140 \\
\cline { 2 - 6 } & Important & 187615 & 91647 & 48.9 & 123 \\
\cline { 2 - 7 } & Standard & 312608 & 87885 & 28.1 & 46 \\
\cline { 2 - 7 } & Total & $\mathbf{6 8 0 ~ 1 4 8}$ & $\mathbf{3 0 2} 497$ & $\mathbf{4 4 . 5}$ & $\mathbf{3 0 9}$ \\
\hline \multirow{3}{*}{$\begin{array}{l}\text { South } \\
\text { Hemisphere }\end{array}$} & Top & 330040 & 272240 & 82.5 & 288 \\
\cline { 2 - 7 } & Important & 596844 & 523650 & 87.7 & 811 \\
\cline { 2 - 7 } & Standard & 989384 & 683565 & 69.1 & 1013 \\
\cline { 2 - 7 } & Total & $\mathbf{1 9 1 6 ~ 2 6 8}$ & $\mathbf{1 4 7 9 4 5 5}$ & $\mathbf{7 7 . 2}$ & $\mathbf{2 1 1 2}$ \\
\hline
\end{tabular}

Table 1: Coverage achieved so far during the first SPIRIT acquisition campaigns in the Northern (July to October 2007) and Southern (December 2007 to April 2008) Hemispheres.

Thus, as of 17 April 2008, 1262 stereoscopic pairs (each covering $60 \mathrm{~km} * 120 \mathrm{~km}$ ) have been collected by SPOT 5 HRS. All the quick-looks (HRS images in 120-m resolution) are available for online consultation on Polar DALI (http://polardali.spotimage.fr:8092/IPY/dalisearch.aspx) after a login has been obtained from the CNES IPY team (hrs_ipy@cnes.fr).

\section{II.3 The SPIRIT Product}

The SPIRIT product has been specifically designed to serve glaciology applications, providing both topography and ortho-image with an absolute horizontal precision of $30 \mathrm{~m} \mathrm{rms}$. It is composed of:

- two 40-m digital terrain models (DTMs) computed using different sets of correlation parameters adapted to different types of relief (the first version is for a gentle topography and the second one for a more rugged one). Altitude (m a.s.1.) in the DTMs are referenced to the EGM96 geoid,

- two reliability masks (one for each DTM) indicating the correlation score during DTM generation and clearly identifying interpolated pixels,

- a 5-m ortho-image derived from the backward HRS raw image.

More details on the SPIRIT product are available at http://www.spotimage.fr/IPY/. DTMs are always derived from a single stereoscopic pair which guarantees that ice elevations from different dates are not merged into a single product. The DTM extraction is performed by the French mapping institute (Institut Géographique National, IGN) following a predefined, 100\% automatic processing method, including no manual intervention and no interactive check against any kind of ground-based measurements. The original HRS stereoscopic pair (raw data) is not delivered. 


\section{EVALUATION OF THE SPIRIT DTMS.}

The main validation site has been the ablation area of a large outlet glacier on the west coast of the Greenland ice sheet, Jakobshavn Isbrae $\left(69^{\circ} \mathrm{N}, 48.7^{\circ} \mathrm{W}\right)$. Additionally, to determine the impact of the terrain characteristics on the accuracy of the SPIRIT DTMs, we have also evaluated DTMs produced on the flat western part of the Devon Ice cap (Canada), on the steeper terrain of the Saint Elias mountain (Alaska and Yukon Territory) and on the intermediate slopes of the western part of the Svalbard Archipelago. These different sites are located in Fig. $2 b$.

The SPIRIT DTMs have been compared with ICESat elevation profiles acquired from 12 March 2007 to 14 April 2007 during the $3 \mathrm{H}$ laser period and from 2 October 2007 to 5 November 2007 during the 3I laser period (Zwally et al., 2002). These two laser periods have been chosen because they were performed before and after the SPOT 5 acquisitions and thus, permit the detection of a likely seasonal contribution (e.g. melting of snow/ice) to the elevation differences. The SPIRIT altitudes are extracted at the center of the ICESat footprint by bilinear interpolation. The difference $\left(Z_{\text {SPIRIT }}-Z_{\text {ICESat }}\right)$ is computed for each point to produce histograms of elevation differences and derive some global statistics (mean, standard deviation).

Note that our comparisons assume that SPIRIT and ICESat data are well-coregistered. Any horizontal mis-registration between the two datasets will lead to errors in elevations especially when the surface slope is important. Consequently, our error budget does not only include SPIRIT elevation errors but also two other sources of errors, both correlated with the surface slope:

1. The first source is due to the fact that ICESat and SPIRIT DTM do not observe exactly the same target on the ground and the bilinear interpolation may not account for the real topography existing between the ICESat and SPIRIT targets. This error, due to the surface curvature, increases with the surface slope

2. Errors in ICESat laser pointing will also contribute to our error budget. For Antarctica, a cross-over analysis has shown that RMS elevation errors increase with surface slope and exceed $25 \mathrm{~cm}$ for slopes larger than $1^{\circ}$ (Shuman et al., 2006). Larger ICESat errors can be expected in steeper, mountainous regions.

The time difference between SPIRIT DTMs and ICESAT data is a third possible contribution to the total error budget (not necessarily correlated with the surface slope). Thus, we provide an upper bound to the SPIRIT elevation errors.

For the sake of simplicity, only version 2 of the SPIRIT DTM is evaluated in the present article and the results for version 1 are not shown. The main differences between the two versions of the DTM can be summarized as follows: (i) a lower percentage of interpolated pixels in version 1 and, (ii) for the non-interpolated pixels, errors that are slightly smaller for version 2 of the DTM.

\section{III.1. DTM validation on Jakobshavn Isbrae (Greenland ice sheet)}

Two nearly cloud-free HRS stereo-pairs were acquired during summer 2007 over Jakobshavn Isbrae within a time interval of 11 days. The first one (24 July 2007) is located on the coast and also includes ice-free regions whereas the second one (4 august 2007) encompass only ice- 
covered areas. The two images present a small overlapping area, including the calving front of the glacier. In Fig. 4 and 5, the ICESat tracks (laser period 3H) are plotted over SPIRIT orthoimages and the histograms of elevation differences between SPIRIT DTMs and ICESat are shown. The statistics on the elevation differences are summarized in Table 2 and Table 3.

For the coastal DTM (Fig. 4a), artifacts due to clouds led to obvious outliers on each extremity of the histogram (Fig. 4b). Clouds during the SPOT 5 HRS (respectively ICESat) acquisitions were detected as they led to large and positive (respectively negative) elevation differences between the two datasets. These outliers can thus easily be detected and removed. After their removal (Fig. 4c), the mean elevation difference is $-0.3 \mathrm{~m}$ with ICESat-3H period (SPIRIT lower than ICESat) and $4.8 \mathrm{~m}$ with ICESat-3I period (SPIRIT higher than ICESat). The standard deviations are respectively $4.8 \mathrm{~m}(\mathrm{~N}=790)$ and $6.3 \mathrm{~m}(\mathrm{~N}=340)$. Part of the mean elevation difference reflects ice thinning or melting of the snow layer between the ICESat-3H (March-April 2007) and SPOT 5 (late July 2007) acquisitions and then between the SPOT 5 and the ICESat-3I period (October-November 2007). The rest may be explained by a small positive bias in the SPIRIT DTM (although a systematic bias in ICESAT cannot be excluded).
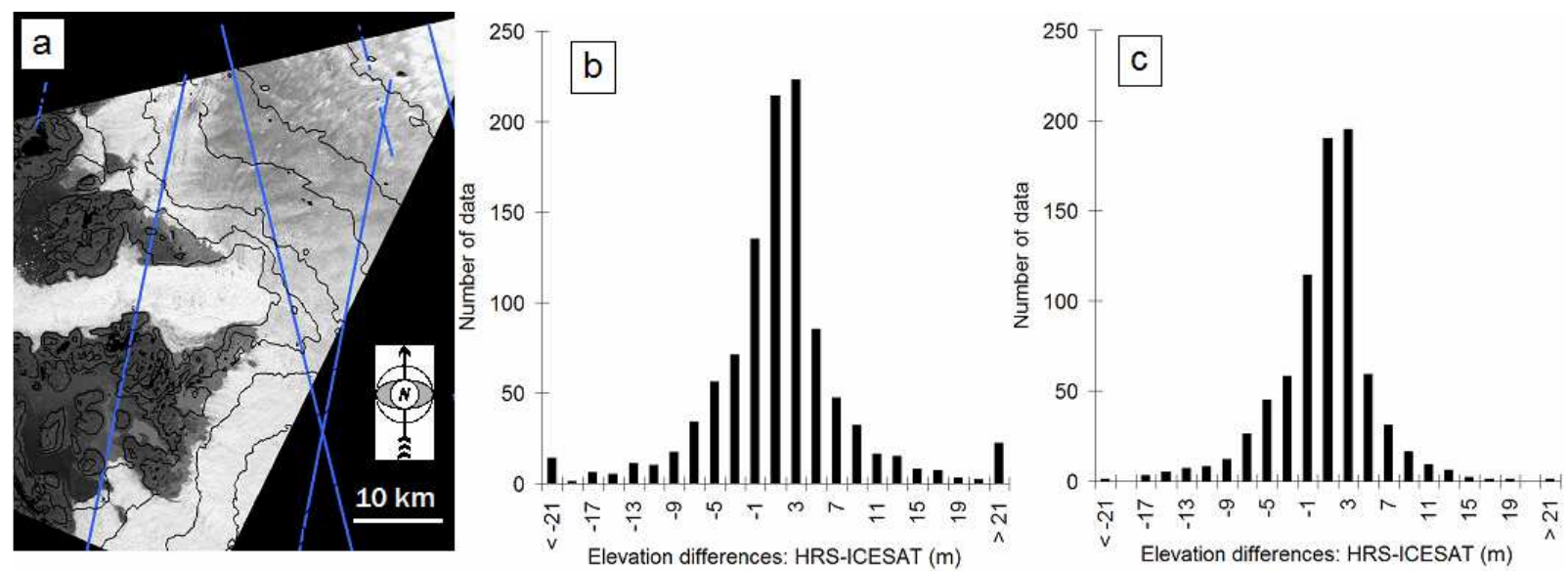

Figure 4: Comparison of SPIRIT and ICESat data over the coastal region of Jakobshavn Isbrae (Greenland). (a) 24 July 2007 SPIRIT ortho-image with the ICESat 3 H tracks overlaid; (b) histogram of the elevation differences between the 24 July 2007 SPIRIT DTM and ICESat elevation profiles; $(c)$ histogram of the elevation differences between the 24 July 2007 SPIRIT DTM and ICESat elevation profiles after excluding outliers with anomalous elevation differences (due to clouds).

Fig. 5 shows the histogram of the elevation differences between the inland DTM derived from the 4 August 2007 images and ICESat-3H laser period. The mean elevation difference is $-0.6 \mathrm{~m}$ whereas the standard deviation is $3.5 \mathrm{~m}(\mathrm{~N}=1621)$. The results of the comparison with ICESat3I laser period are given in Table 3. As for the coastal DTM, there is a significant lowering (3 to $4 \mathrm{~m}$ ) of the glacier surface between the two ICESAT campaigns.

The fact that both SPIRIT DTMs were acquired on the flat, highly textured ablation area of the Greenland ice sheet may explain these excellent results. The good overall quality of the DTMs is also confirmed by the low percentage of interpolated pixels (Table 2). 

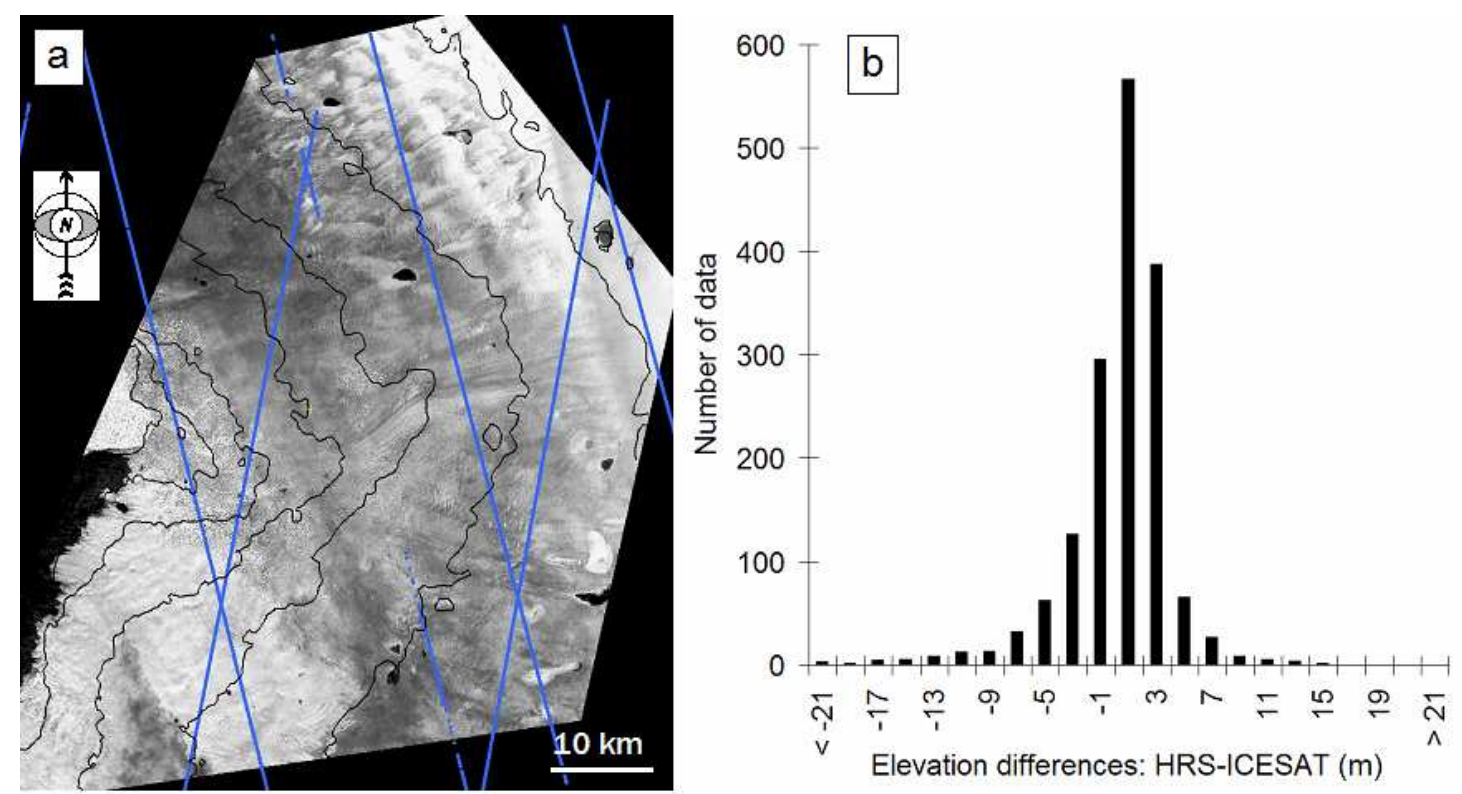

Figure 5: Comparison of the SPIRIT and ICESat data over the ablation area of Jakobshavn Isbrae (Greenland). (a) 4 August 2007 SPIRIT ortho-image with the ICESat 3 H tracks overlaid; (b) histogram of the elevation differences between the 4 August 2007 SPIRIT DTM and ICESat elevation profiles.

\section{III.2 Other SPIRIT validation sites}

Further comparisons have been performed between ICESat 3H and 3I laser periods and SPIRIT DTMs in order to estimate the DTM quality on different types of slopes and landscapes (Fig. 6ac). Our targeted areas were the steep relief of the St Elias Mountains (Alaska, $61^{\circ} \mathrm{N}, 140.5^{\circ} \mathrm{W}$ ), the smooth topography of the Devon Ice Cap (Canadian arctic, $75.3^{\circ} \mathrm{N}, 83^{\circ} \mathrm{W}$ ) and the intermediary slopes on the western part of Svalbard $\left(79^{\circ} \mathrm{N}, 15^{\circ} \mathrm{E}\right)$.
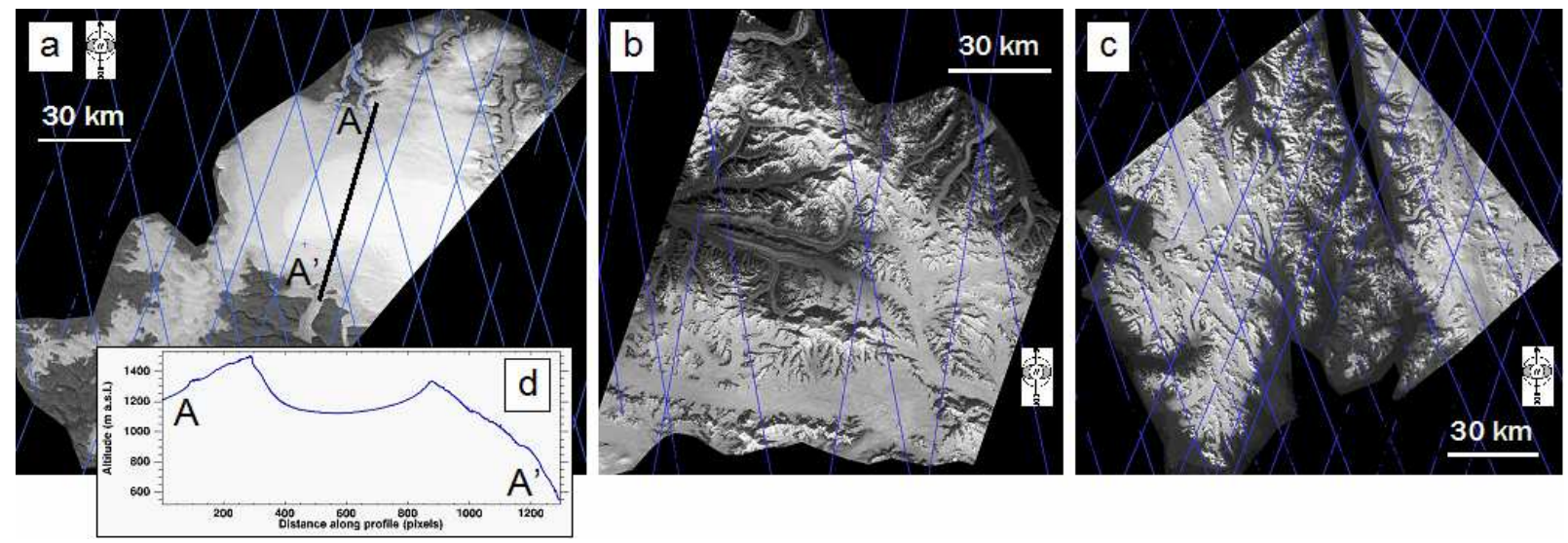

Figure 6: SPIRIT ortho-images over: (a) Devon Ice Cap (20 August 2007); (b) St Elias Mountains (13 September 2007); (c) West Svalbard (1 September 2007). The ICESat 3 H tracks are overlaid; (d) Elevation profile across the Devon Ice cap extracted from the SPIRIT DTM. Above the snowline, the correlation failed during the DTM generation and the interpolation of large gaps in the DTM led to an erroneous caldeira-like topography. 
To compare SPIRIT and ICESat data, we followed the same procedure as for Jakobshavn Isbrae. Table 2 and Table 3 show the percentage of interpolated pixels, the mean and standard deviation of the elevation differences (after exclusion of interpolated and cloudy pixels) with the two ICESat laser periods $3 \mathrm{H}$ and 3I.

\begin{tabular}{lllrrrr}
\hline Region & $\begin{array}{l}\text { Date } \\
\text { SPIRIT }\end{array}$ & $\begin{array}{l}\text { Date } \\
\text { ICESAT }\end{array}$ & $\begin{array}{l}\text { Mean } \\
(\mathbf{m})\end{array}$ & $\begin{array}{l}\text { RMS } \\
(\mathbf{m})\end{array}$ & $\begin{array}{l}\text { Number } \\
\text { of data }\end{array}$ & $\begin{array}{l}\text { Interpolated } \\
\text { pixels (\%) }\end{array}$ \\
\hline St Elias & 13 Sept. 2007 & 28 March 2007 & 3.5 & 8.9 & 2267 & 31.5 \\
\hline Devon & 20 Aug. 2007 & 28 March 2007 & -0.5 & 4.6 & 3852 & 33.2 \\
\hline Svalbard & 1 Sept. 2007 & 28 March 2007 & -5.5 & 6.8 & 4185 & 32.8 \\
\hline Jakobshavn Coast & 24 July 2007 & 26 March 2007 & -0.3 & 4.8 & 790 & 5.6 \\
\hline Jakobshavn Inland & 4 Aug. 2007 & 31 March 2007 & -0.6 & 3.5 & 1621 & 15.8 \\
\hline
\end{tabular}

Table 2: Statistics (mean and RMS) on the elevation differences between SPIRIT DTMs and ICESat $3 H$ profiles on five areas in the Northern Hemisphere. The date of the ICESAT data is the mean date of all valid (=cloud free) ICESAT footprints. The "number of data" column corresponds to the number of pixels for which both ICESat and SPIRIT elevations where valid (after excluding interpolated and cloudy pixels) and used to compute the mean and standard deviations. The percentage of interpolated pixels (last column) is given here for the whole SPIRIT DTMS (and not only for pixels where ICESat profiles were available).

The number of interpolated pixels for the three sites is higher than for the ablation area of Jakobshavn Isbrae. Data gaps covering about one third of the DTMs had to be interpolated by IGN to obtain a continuous representation of the topography. As expected from previous works (e.g., Berthier and Toutin, 2008), most of these interpolated pixels are located on the flat accumulation area of the icefields and ice caps where stereo-images lack radiometric contrast and their correlation breaks down. When these data gaps cover large area, the interpolation can lead to a totally unrealistic topography. For example, on the Western part of the Devon ice cap, large areas above the snowline had to be interpolated which led to an unexpected and erroneous "caldeira-like" topography at the center of the ice cap (Fig. 6.d). This observation confirms the importance of the masks included in the SPIRIT product, because they clearly indicate to the user where elevation data are reliable and where they were interpolated.

Once interpolated pixels are excluded, biases of SPIRIT DTMs with laser period $3 \mathrm{H}$ are reasonable, ranging from $-5.5 \mathrm{~m}$ (Svalbard) to $+3.5 \mathrm{~m}$ (St Elias Mountains). For the three other study areas, the bias is smaller than one meter (Table 2). Similar biases are obtained when SPIRIT elevations are compared to the 3I laser period (Table 3), although the mean differences are all more negative (or less positive) due to the melting of the snow layer and/or the thinning of the glaciers between laser period 3H (March-April 2007) and 3I (October-November 2007). Part of these systematic differences may be due to errors in the position and attitude of the satellite (Bouillon et al., 2006) and are inherent to the automatic processing of the images without additional ground control points. Such systematic biases need to be evaluated and corrected before using the SPIRIT DTM to compute elevation differences (Berthier et al., 2006). We have shown here the potential of using sparse but accurate ICESat elevation profiles to estimate and correct the bias of large scale SPIRIT DTMs. This strategy is recommanded for SPIRIT users interested in mapping ice elevation changes. If the mean differences are averaged for the five different regions, SPIRIT elevations are $0.7 \mathrm{~m}$ lower than the $3 \mathrm{H}$ laser period and 0.9 higher than the 3I laser period which is in agreement with an expected seasonal signal of surface lowering 
between March-April (3H) and October-November (3I) due to the spring/summer melting of the winter snow-pack in the Northern Hemisphere.

\begin{tabular}{lllrrrr}
\hline Region & $\begin{array}{l}\text { Date } \\
\text { SPIRIT }\end{array}$ & $\begin{array}{l}\text { Date } \\
\text { ICESAT }\end{array}$ & $\begin{array}{l}\text { Mean } \\
(\mathbf{m})\end{array}$ & $\begin{array}{l}\text { RMS } \\
(\mathbf{m})\end{array}$ & $\begin{array}{l}\text { Number } \\
\text { of data }\end{array}$ \\
\hline St Elias & 13 Sept 2007 & 17 Oct. 2007 & 6.0 & 8.8 & 1599 \\
\hline Devon & 20 Aug. 2007 & 14 Oct. 2007 & 0.1 & 3.9 & 2611 \\
\hline Svalbard & 1 Sept 2007 & 17 Oct. 2007 & -4.7 & 6.7 & 2290 \\
\hline Jakobshavn Coast & 24 July 2007 & 27 Oct. 2007 & 4.8 & 6.3 & 341 \\
\hline Jakobshavn Inland & 4 Aug. 2007 & 27 Oct. 2007 & 3.2 & 3.8 & 1087 \\
\hline
\end{tabular}

Table 3: Same statistics as in Table 2 except that SPIRIT DTMs are compared to elevations from the ICESat 3I campaign, performed in October and November 2007.

In agreement with previous works (e.g., Jacobsen, 2004), RMS elevation errors in the DTMs are linearly correlated with the tangent of the surface slope (Fig. 7). It implies that, in the absence of other reference topographic data (such as ICESat or field data), the RMS error of SPIRIT DTMs (interpolated pixels excluded) can be roughly inferred from the mean slope of the region of interest. Note that the linear relationship between DTM error and the surface slope remains nearly unchanged when ice and land are split into two categories. Thus, for non-interpolated pixels, the elevation error in the SPIRIT DTM does not depend (or only weakly) on the surface state. However, the surface state mainly controls the radiometry dynamics in the images and thus, the percentage of interpolated pixels.

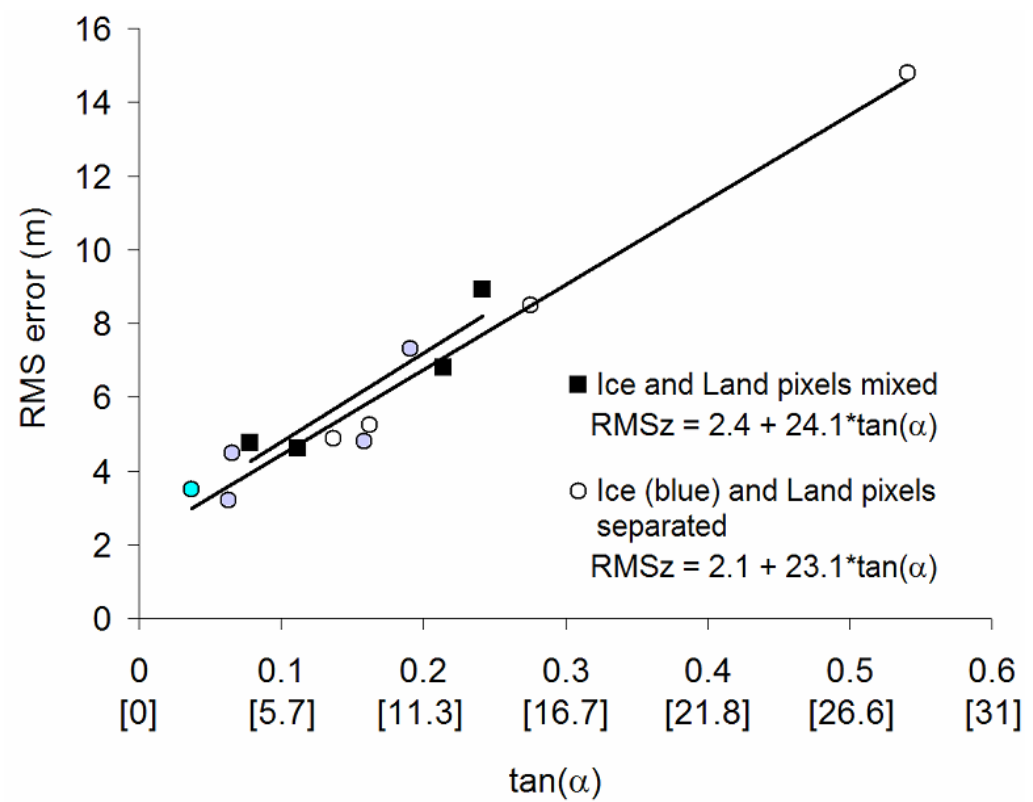

Figure 7: Root mean square (RMS) elevation errors in the different SPIRIT DTMs as a function of the tangent of the surface slope (noted $\alpha$ ). In brackets, we indicated the corresponding absolute slope in degrees. The RMS has been estimated in two cases depending whether ice and non-ice pixels are mixed (square symbols) or distinguished (rounded symbols). All interpolated or cloudy pixels in the SPIRIT DTMs have been excluded before computing these statistics. 


\section{First GLACIOLOGICAL RESULTS USING SPIRIT DTMS AND ORTHO-IMAGES: RECENT EVOLUTION OF JAKOBSHAVN ISBRAE.}

Jakobshavn Isbrae is one of the major ice streams in Greenland. It discharges 35 billions tons of icebergs each year, representing $7 \%$ of the ice rejected by the Greenland ice sheet in the oceans (Rignot and Kanagaratnam, 2006). This discharge has recently increased due to the acceleration of the glacier from $\sim 17 \mathrm{~m} /$ day (or $6.3 \mathrm{~km} / \mathrm{yr}$ ) in 1985 to $\sim 35 \mathrm{~m} /$ day (or $12.6 \mathrm{~km} / \mathrm{yr}$ ) in 2006 (Howat et al., 2007). The retreat of the calving front has been $40 \mathrm{~km}$ since 1850 . But its evolution has not been constant. From 1850 to 1964, the calving front shrunk back at a mean speed of 0.3 $\mathrm{km} / \mathrm{yr}$ but then stagnated from 1964 to 2000. After 2000, it began retreating again at a rate of 3 $\mathrm{km} / \mathrm{yr}$ (Csatho et al., 2008).

\section{IV.1. Thinning of the ice stream.}

As the two SPIRIT DTMs have a small common part including the calving front of the glacier, we can estimate the 11-day elevation difference (Fig. 8).

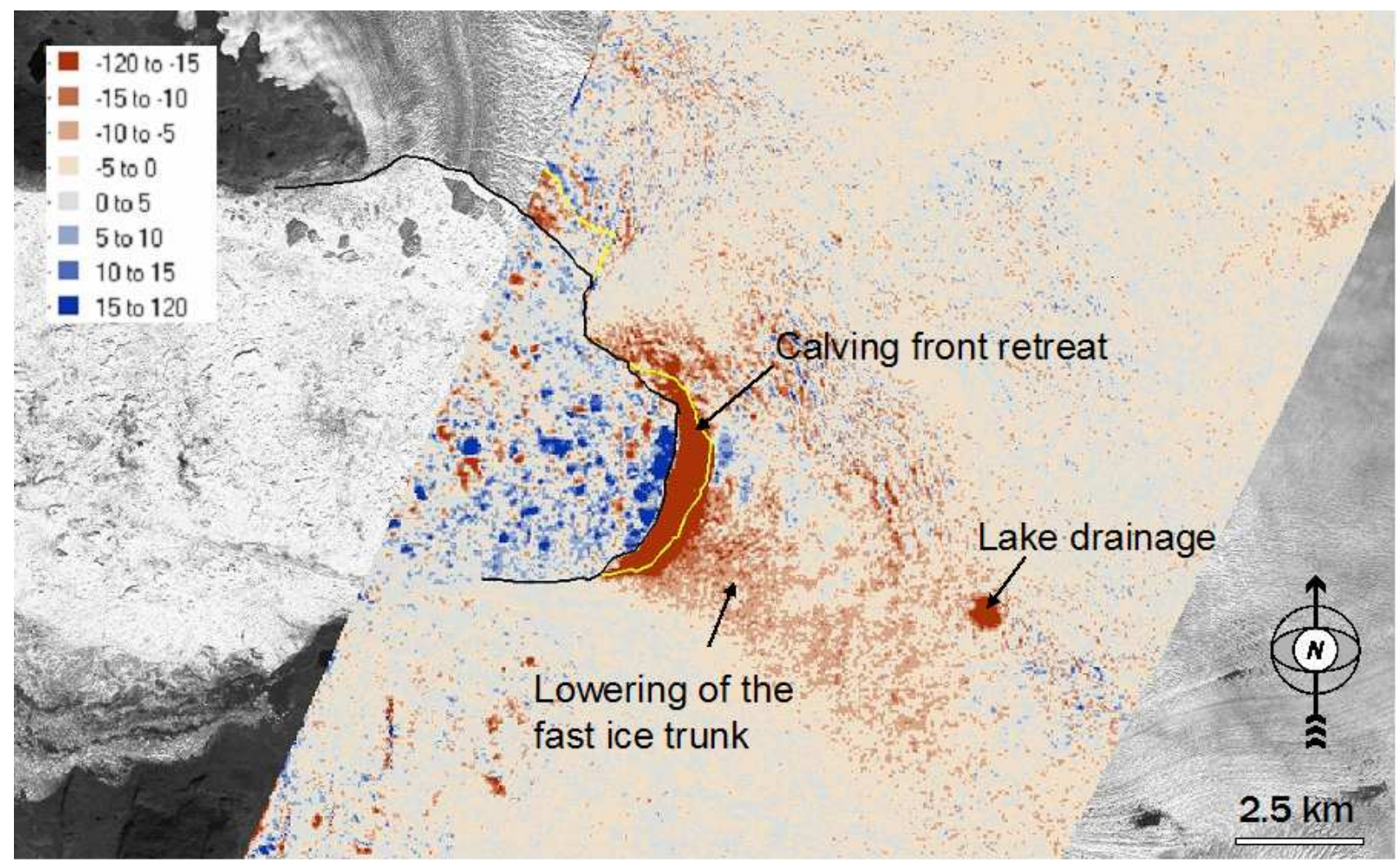

Figure 8: Elevation differences ( $m$ ) between the two SPIRIT DTMs (4 August 2007 - 24 July 2007) of Jakobshavn Isbrae. The calving front is drawn in black (24 July 2007) and in yellow (4 August 2007).

Away from the fast ice stream, the differences are generally small (absolute mean difference of $0.5 \mathrm{~m}$ with a standard deviation of $4.7 \mathrm{~m}$ ) proving the good consistency of the two SPIRIT DTMs. Yet, within only 11 days, two regions have experienced a clear lowering of the surface: 
- The drainage of a supra-glacial lake covering $0.38 \mathrm{~km}^{2}$ is clearly depicted with a maximum surface lowering of $40 \mathrm{~m}$ and an average lowering of $21 \mathrm{~m}$. The volume of water that drained from this lake is about $8,000,000 \mathrm{~m}^{3}$.

- Close to the calving front, the altitudes have lowered by about $100 \mathrm{~m}$. This is explained by a large calving event that also resulted in a $700 \mathrm{~m}$ retreat of the calving front. Just upstream of the calving front, the main ice trunk has thinned by 5 to $10 \mathrm{~m}$ (in 11 days). Surface rising in the fjord (in blue in Fig. 8) is due to the icebergs that were calved.

The 24 July 2007 SPIRIT DTM has also been compared with a 17 April 2003 ASTER DTM to map the 4-year elevation difference (Fig. 9). The retreat of the calving front between 2003 and 2007 is the most striking feature. The thinning has been particularly strong (up to $100 \mathrm{~m}$ ) along the fastest part of the glacier. Upstream of the 2007 calving front, the pattern of elevation change is complex but it clearly shows the propagation of the thinning in the upslope direction. The secondary branch of the glacier in the northern direction also exhibits the upslope diffusion of the outlet thinning.

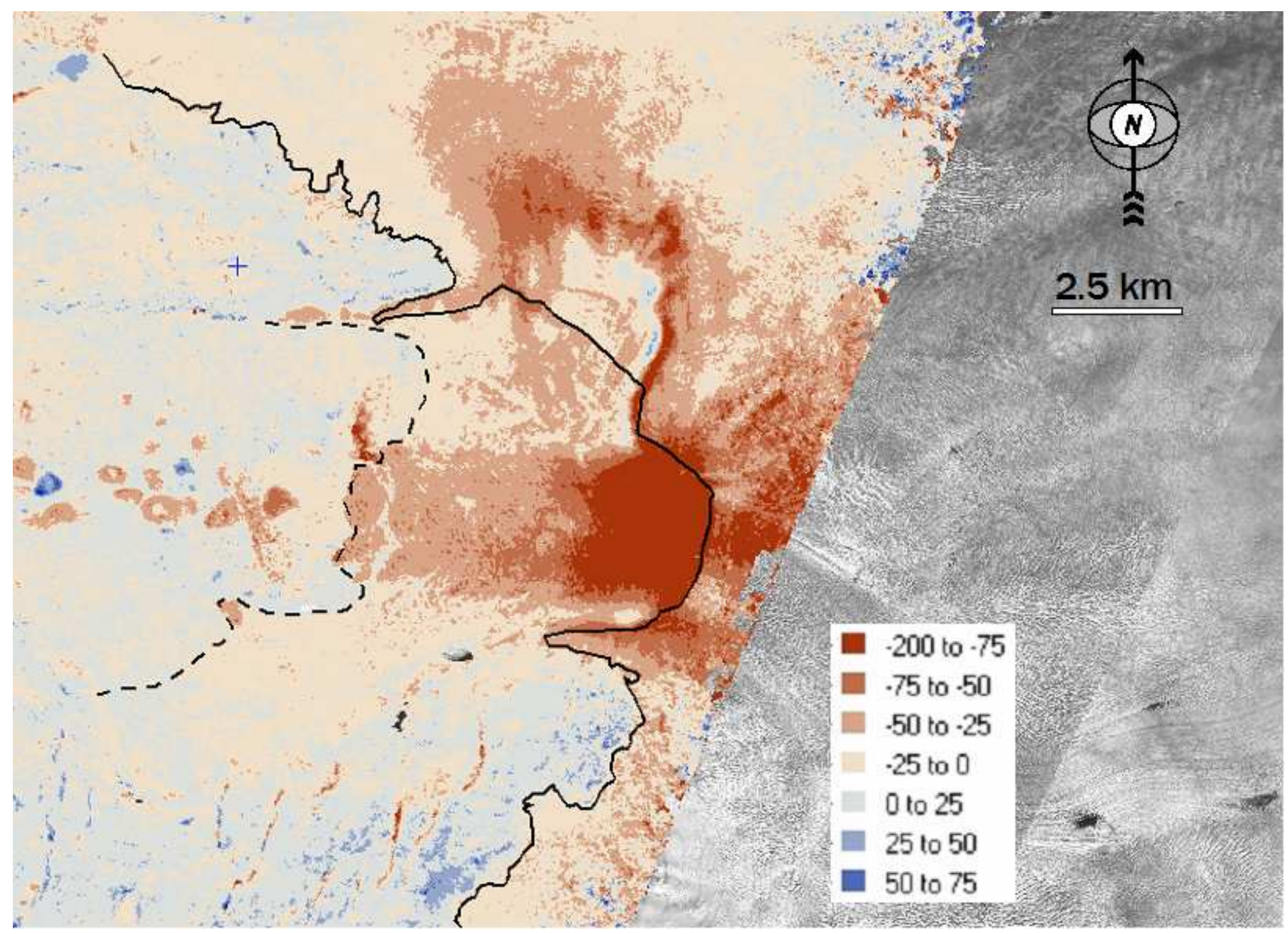

Figure 9: Elevation differences ( $m$ ) between the 24 July 2007 SPIRIT DTM and the 17 April 2003 ASTER DTM of Jakobshavn Isbrae. The April-2003 calving front is drawn with a dashed black line, whereas it is shown with a solid black line in July-2007.

We have also compared the SPIRIT DTM to ICESat data from October 2003 (2A laser period) in order to quantify the elevation changes of Jakobshavn Isbrae up to an altitude of $1100 \mathrm{~m}$ (Fig. 
10). A strong thinning ( 20 to $40 \mathrm{~m}$ in about 4 years) is observed. Interestingly, the rapid thinning is restricted to the fast flowing trunk of the glacier.

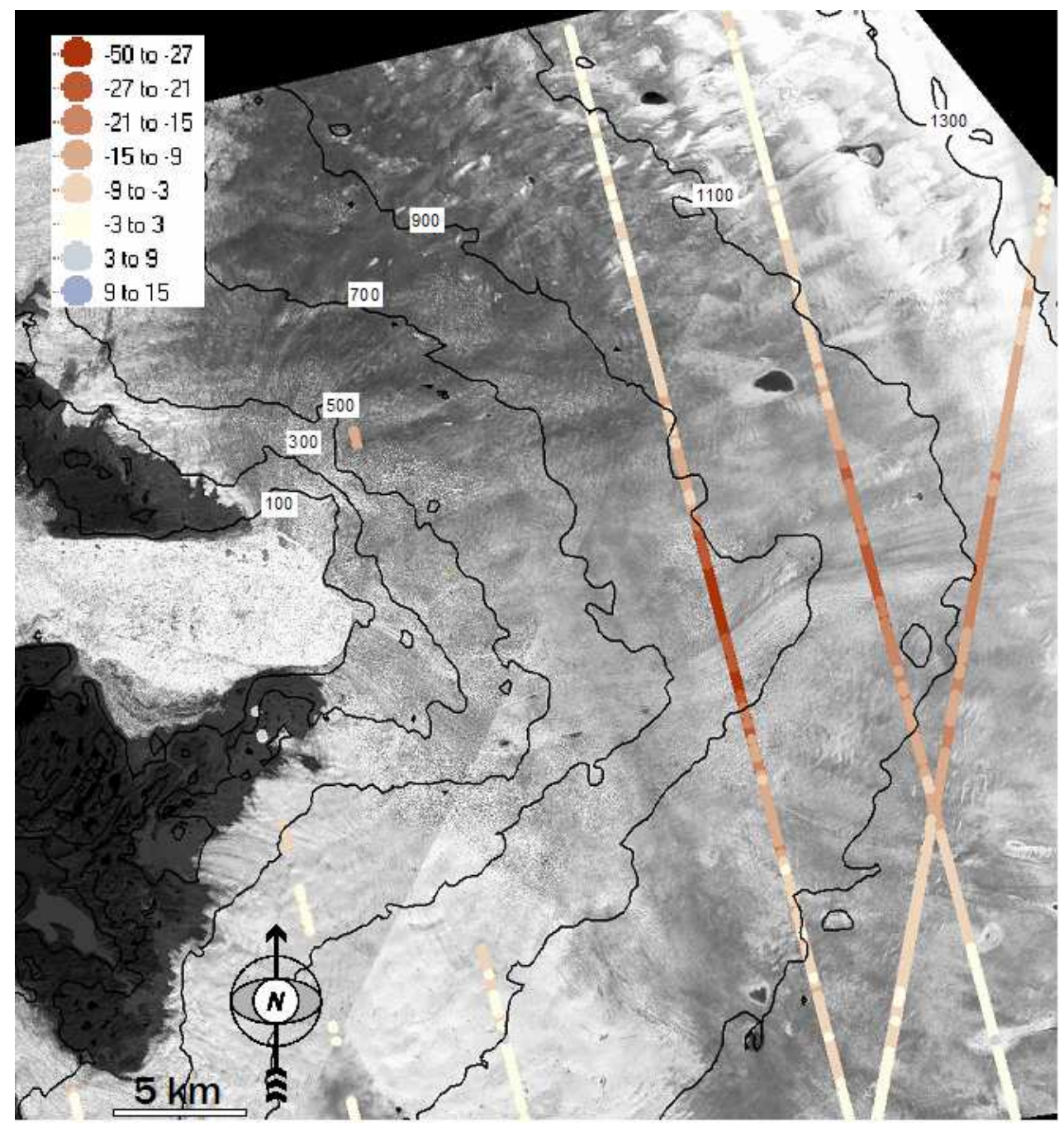

Figure 10: Elevation differences of Jakobshavn Isbrae derived by comparing ICESat data (laser period $2 A$ in October 2003) and the 4 August 2007 SPIRIT DTM. The altitude contour lines (thin black line) start at $100 \mathrm{~m}$ a.s.l. and are displayed every $200 \mathrm{~m}$ up to $1300 \mathrm{~m}$ a.s.l.

\section{IV.2. Velocity field during summer 2007.}

As the two SPIRIT ortho-images are acquired 11-day apart and present an overlapping region, they can be cross-correlated to map the displacement of surface features (Berthier et al., 2005; Scambos et al., 1992). The velocity map clearly shows that the region of fast moving ice is restricted to a 4-km wide channel (Fig. 11). The highest velocity is measured at the calving front and reaches $15.5 \mathrm{~km} / \mathrm{yr}(42.5 \mathrm{~m} /$ day $)$ confirming that Jakobshavn Isbrae is probably the fastest glacier on Earth (Howat et al., 2007). 


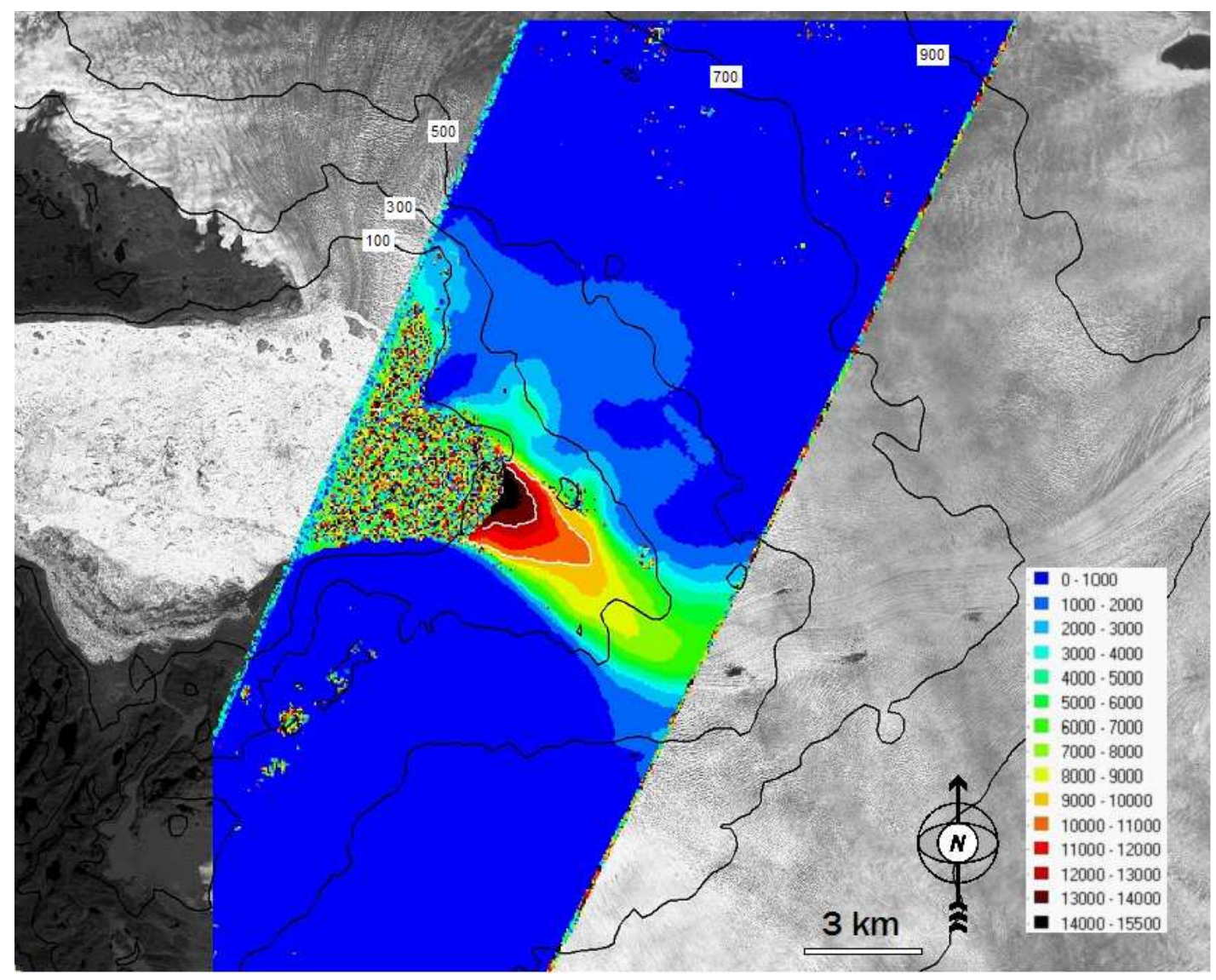

Figure 11: Map of the velocity field $(\mathrm{m} / \mathrm{yr})$ of Jakobshavn Isbrae close to its calving front between July $24^{\text {th }} 2007$ and August $4^{\text {th }}$ 2007. The $10 \mathrm{~km} / \mathrm{yr}$ and $13 \mathrm{~km} / \mathrm{yr}$ velocity contour lines are shown (thin white lines). The altitude contour lines (black lines) start at $100 \mathrm{~m}$ a.s.l. and are displayed every $200 \mathrm{~m}$ up to 900 m a.s.l.

\section{CONCLUSION}

During the fourth international polar year, the SPIRIT project (SPOT 5 stereoscopic survey of Polar Ice: Reference Images and Topographies) will permit to build a large archive of SPOT 5 HRS high-resolution stereoscopic images. DTMs and ortho-images will be generated from these stereoscopic image pairs for selected target areas and will be delivered for free to the scientific community. The SPIRIT project will thus help to improve our knowledge of the topography of polar ice masses. Together with other IPY satellite acquisitions coordinated by the GIIPSY program, SPIRIT will contribute to build an IPY snapshot of the poles in order to observe and understand recent and future evolutions of the polar cryosphere.

The potential of the SPIRIT product for glaciological studies has been demonstrated in the case of Jakobshavn Isbrae (West Greenland). Using SPIRIT DTMs and ortho-images, we confirm that the fastest glacier on Earth is thinning rapidly. One important observation is that the thinning is mainly restricted to the fast flowing part of the glacier. This is expected as ice dynamics is known to be the main driver of ice stream thinning (Thomas et al., 2003). Our finding implies that basin- 
wide polynomial extrapolation of elevation changes measured within the first $50-\mathrm{km}$ inland of the calving front to the rest of the drainage basin (Stearns and Hamilton, 2007) may not be correct.

In the near future, our efforts to validate SPIRIT data will go on. We will analyze DTMs generated from HRS stereo-pairs acquired on the less-textured landscapes of Antarctica to test whether the promising results obtained in the Northern Hemisphere are confirmed. We also invite all users of the SPIRIT product to assess and report on its accuracy through comparison with their own data derived from other space-borne sensor or collected in the field during IPY. In the coming years, the Cryosat-2 mission, scheduled to be launched in March 2009 by ESA, could also benefit of the SPIRIT DTMs to calibrate the SARin mode over polar ice caps and glaciers.

\section{ACKNOWLEDGMENTS}

The comments by two anonymous reviewers and Eberhard Gülch (Associate Editor) helped to clarify our manuscript. We also would like to thank Ted Scambos (NSIDC, Colorado) for providing his MODIS mosaics of Antarctica (MOA) and Greenland, Eric Rignot (JPL, Pasadena) for sharing his ice velocity mosaics of Antarctica and Greenland, D. Korn and T. Haran (NSIDC, Colorado) for their help with ICESat data. Julian Dowdeswell (SPRI, Cambridge) suggested some SPIRIT targets in the Arctic. Glacier outlines from the Digital Chart of the World were kindly provided by Bruce Raup (NISDC, Colorado). The ASTER April-2003 image of Jakobshavn Isbrae was obtained for free thanks to the GLIMS program (Global Land Ice Measurements from Space, http://www.glims.org/). E.B. was supported by the TOSCA "TOP GLACES API" proposal. We also acknowledge all the sponsoring agencies (ICSU, WMO) of the International Polar Year and the framework provided by the GIIPSY project (PI: Ken Jezek). The CNES is acknowledged for the complete funding of the SPIRIT project.

\section{REFERENCES}

Berthier, E., Arnaud, Y., Baratoux, D., Vincent, C., Remy, F., 2004. Recent rapid thinning of the "Mer de Glace" glacier derived from satellite optical images. Geophysical Research Letters, 31(17), L17401.

Berthier, E., Arnaud, Y., Vincent, C., Remy, F., 2006. Biases of SRTM in high-mountain areas: Implications for the monitoring of glacier volume changes. Geophysical Research Letters, 33(8), L08502.

Berthier, E., Toutin, T., 2008. SPOT5-HRS digital elevation models and their application to the monitoring of glacier elevation changes. A case study in North-West Canada and Alaska. Remote Sensing of Environment, 112(5), 2443-2454.

Berthier, E., Vadon, H., Baratoux, D., Arnaud, Y., Vincent, C., Feigl, K.L., Remy, F., Legresy, B., 2005. Surface motion of mountain glaciers derived from satellite optical imagery. Remote Sensing of Environment, 95(1), 14-28.

Bouillon, A., Bernard, M., Gigord, P., Orsoni, A., Rudowski, V., Baudoin, A., 2006. SPOT 5 HRS geometric performances: Using block adjustment as a key issue to improve quality of DEM generation. ISPRS Journal of Photogrammetry and Remote Sensing, 60(3), 134-146.

Csatho, B., Schenk, T., Van der Veen, C.J., Krabill, W., 2008. Intermittent thinning of Jakobshavn Isbræ, West Greenland, since the Little Ice Age. Journal of Glaciology, 54(184), 131-144.

Howat, I.M., Joughin, I., Scambos, T.A., 2007. Rapid Changes in Ice Discharge from Greenland Outlet Glaciers. Science, 315(5818), 1559-1561.

IPCC International Panel on Climate Change, 2007. Climate Change 2007: The Scientific Basis. Cambridge Univ. Press, New York. 
Jacobsen, K., 2004. DEM generation by SPOT HRS, ISPRS XXth Congress, Istanbul.

Kaser, G., Cogley, J.G., Dyurgerov, M.B., Meier, M.F., Ohmura, A., 2006. Mass balance of glaciers and ice caps: Consensus estimates for 1961-2004. Geophysical Research Letters, 33(19).

Parrenin, F., Remy, F., Ritz, C., Siegert, M.J., Jouzel, J., 2004. New modeling of the Vostok ice flow line and implication for the glaciological chronology of the Vostok ice core. Journal of Geophysical Research-Atmospheres, 109(D20102).

Rabus, B., Eineder, M., Roth, A., Bamler, R., 2003. The shuttle radar topography mission - a new class of digital elevation models acquired by spaceborne radar. ISPRS Journal of Photogrammetry and Remote Sensing, 57(4), 241-262.

Raup, B.H., Kieffer, H.H., Hare, T.M., Kargel, J.S., 2000. Generation of data acquisition requests for the ASTER satellite instrument for monitoring a globally distributed target: Glaciers. IEEE Transactions on Geoscience and Remote Sensing, 38(2), 1105-1112.

Remy, F., Parrenin, F., 2004. Snow accumulation variability and random walk: how to interpret changes of surface elevation in Antarctica. Earth and Planetary Science Letters, 227(3-4), 273-280.

Remy, F., Shaeffer, P., Legresy, B., 1999. Ice flow physical processes derived from the ERS-1 highresolution map of the Antarctica and Greenland ice sheets. Geophysical Journal International, 139(3), 645-656.

Rignot, E., 2006. Changes in ice dynamics and mass balance of the Antarctic ice sheet. Philosophical Transactions of the Royal Society a-Mathematical Physical and Engineering Sciences, 364(1844), $1637-1655$.

Rignot, E., Kanagaratnam, P., 2006. Changes in the velocity structure of the Greenland ice sheet. Science, 311(5763), 986-990.

Ritz, C., Rommelaere, V., Dumas, C., 2001. Modeling the evolution of Antarctic ice sheet over the last 420,000 years: Implications for altitude changes in the Vostok region. Journal of Geophysical Research-Atmospheres, 106(D23), 31943-31964.

Rott, H., Skvarca, P., Nagler, T., 1996. Rapid Collapse of Northern Larsen Ice Shelf, Antarctica. Science, 271(5250), 788-792.

Scambos, T., Dutkiewicz, M.J., Wilson, J.C., Bindschadler, R.A., 1992. Application of image crosscorrelation to the measurement of glacial velocity using satellite image data. Remote Sensing of Environment, 42, 177-186.

Scambos, T.A., Bohlander, J.A., Shuman, C.A., Skvarca, P., 2004. Glacier acceleration and thinning after ice shelf collapse in the Larsen B embayment, Antarctica. Geophysical Research Letters, 31(18).

Scambos, T.A., Haran, T.M., Fahnestock, M., Painter, T.H., Bohlander, J., 2007. MODIS-based Mosaic of Antarctica (MOA) Data Sets: Continent-wide Surface Morphology and Snow Grain Size. Remote Sensing of Environment, 111, 242-257.

Shuman, C.A., Zwally, H.J., Schutz, B.E., Brenner, A.C., DiMarzio, J.P., Suchdeo, V.P., Fricker, H.A., 2006. ICESat Antarctic elevation data: Preliminary precision and accuracy assessment. Geophysical Research Letters, 33(7), L07501.

Stearns, L.A., Hamilton, G.S., 2007. Rapid volume loss from two East Greenland outlet glaciers quantified using repeat stereo satellite imagery. Geophysical Research Letters, 34(L05503).

Thomas, R.H., Abdalati, W., Frederick, E., Krabill, W.B., Manizade, S., Steffen, K., 2003. Investigation of surface melting and dynamic thinning on Jakobshavn Isbrae, Greenland. Journal of Glaciology, 49(165), 231-239.

Toutin, T., 2001. Elevation modelling from satellite visible and infrared (VIR) data. International Journal of Remote Sensing, 22(6), 1097-1125.

Zwally, H.J., Schutz, B., Abdalati, W., Abshire, J., Bentley, C., Brenner, A., Bufton, J., Dezio, J., Hancock, D., Harding, D., Herring, T., Minster, B., Quinn, K., Palm, S., Spinhirne, J., Thomas, R., 2002. ICESat's laser measurements of polar ice, atmosphere, ocean, and land. Journal of Geodynamics, 34(3-4), 405-445. 